\title{
Dilemmas of medical ethics in the Canadian Penitentiary Service
}

\author{
Chuni Roy Regional Psychiatric Centre, Abbotsford, British Columbia, Canada
}

There is a unique hospital in Canada - and perhaps in the world - because it is built outside prison walls and it exists specifically for the psychiatric treatment of prisoners. It is on the one hand a hospital and on the other a prison. Moreover it has to provide the same quality and standard of care which is expected of a hospital associated with a university.

From the time the hospital was established moral dilemmas appeared which were concerned with conflicts between the medical and custodial treatment of prisoners, and also with the attitudes of those having the status of prisoner-patient. Dr Roy describes these dilemmas and attitudes, and in particular a special conference which was convened to discuss them. Not only doctors and prison officials took part in this meeting but also general practitioners, theologians, philosophers, ex-prisoners, judges, lawyers, Members of Parliament and Senators. This must have been a unique occasion and Dr Roy's description may provide the impetus to examine these prison problems in other settings.

The Canadian Penitentiary Service is a Federal agency under the Ministry of the Solicitor General of Canada responsible for the care and custody of federal inmates who receive a sentence of two years and above. At any given time there are more than 9000 persons incarcerated in different federal penitentiaries across Canada.

Until 1972 the medical services were primarily concerned with the physical care of the inmates and consequently the issues were simple; in caring for prisoners the physician hardly ever faced ethical dilemmas, except on the question of forced feeding. Contrary to the Tokyo Declaration, which strictly forbade the physician to feed a prisoner forcibly when that prisoner was capable of forming an unimpaired and rational judgment concerning the consequences of voluntary refusal, in Canada it is considered that the care of prisoners who refuse nourishment should include artifical feeding (The Care of Prisoners).

Since 1972, following the historic acceptance by the Canadian Government of the Chalke Committee Report, there has been a considerable expansion of the health care services in Canadian penitentiaries. Until then only a handful of psychiatrists was engaged in providing psychiatric services and in a manner which was considered totall $\overrightarrow{\ddot{z}}$ unsatisfactory.

Development of psychiatric services in Canaiv dian prisons

Canada, like many other countries, has been acutely aware of the fact that in every prison there exist 9 number of inmates who are either mentally ill of emotionally disturbed. From time to time the Government of Canada has appointed commissiong to investigate the matter and produce genera reocmmendations, but it was not until 197 I that group of psychiatrists, under the chairmanship of. Dr Chalke, was asked to look into this matter seri ${ }^{2}$ ously and make specific recommendations, and in May 1972 they submitted their report with specifis recommendations (Chalke, 1973). They estimates that at least one out of ro inmates in Federa penitentiaries requires psychiatric care; furthermorö they concluded that the provincial psychiatrio hospitals had not been able to provide the services which are necessary and therefore they strongly recommended that the nucleus of health care services should be built outside the penitentiaries and thus. they gave birth to the concept of regional medical centres for prisoners. They conceived five such medical centres across the country to provide the necessary services for five regions in Canada.

The acceptance of this report opened a new era of medical initiative of the Canadian Penitentiary Service. On I9 June 1972, less than six weeks after th8 submission of the Chalke report, the first autonomous medical centre, under the direction of a medical. director, opened in Abbotsford, British Columbian Despite a general enthusiasm amongst the prison administrators and members of the medicat profession, the policy was challenged by manyo (Desroches, 1973; Erickson, 1974; Cormier, r973) Despite these criticisms the Centre has made considerable progress over the last four years.

Within two years the Centre became a legat hospital within the meaning of the British Columbiæ Hospital Act, Section 2, and under Section 4(2) of the British Columbia Mental Health Act. This recognition by the provincial health authority mads the Centre a unique institution in Canada. At the time of writing it is the only hospital in Canads which enjoys the dual responsibility of being 
penitentiary on the one hand and a hospital on the other. In September 1974 the Centre became the first university-associated penitentiary hospital after a formal agreement had been reached between the President of the University of British Columbia and the Honourable Solicitor General of the Government of Canada. The agreement committed the Centre to provide the same quality and standard of care which is expected of a university-associated hospital. The Centre presently has 138 beds, five full-time psychiatrists, four full-time psychologists, a department of social work and a large number of trained psychiatric nurses. It is fairly correct to say that the Centre has now achieved national distinction.

With the progressive growth of the Centre the expectations of the public and the prison administrators have naturally increased; so have the problems. Initially the dilemma was strictly in relation to the role of the Centre in relation to other remedial institutions but gradually problems were perceived in different areas, one of which was in the field of medical ethics.

\section{Specific dilemmas of medical ethics in the care of criminal patients in Canada}

The purpose of this paper is not to discuss the basic issue of ethics, or even certain inherent problems associated with medical ethics as many authors have discussed these issues in detail (Campbell, 1972; Davidson, 1957; Gelfend, 1968; McFadden, 1967; Thompson, 1976). This paper will attempt to highlight some of the specific dilemmas of medical ethics as they are being encountered in the day-to-day care of the criminal patients in the Canadian Penitentiary Service. These dilemmas appear to be specific in the field of psychiatric care more than anywhere else. The author's experience is primarily based on his work at the Regional Psychiatric Centre in Abbotsford, but it applies in general to all the penitentiaries across Canada.

CRITERIA FOR ADMISSION AND THE ISSUE OF VOLUNTARY VERSUS INVOLUNTARY TREATMENT

Since the Centre is a hospital it is logical to expect that the criteria of admission will be the same as those of a non-criminal institution. The question to ask, obviously, is whether or not the mental condition of the inmate is such that had he not been a criminal, he would have been transferred to an ordinary psychiatric hospital for the treatment of his mental state. If the answer is in the affirmative then the inmate should be transferred to the Centre with his voluntary permission. While the policy appears simple to follow, in practice it has caused enormous difficulties. First of all, the local prison administrators were disappointed. They expected that the Centre would admit inmates who were causing behavioural problems in different institutions, and, furthermore, since they were prisoners and society expected that the prison should try to rehabilitate them, it was argued that the consent of the prisoners was of little relevance. Some medical colleagues felt strongly that although the Centre is a hospital the mandate of medicine goes beyond the ordinary concept of illness and health. It was argued by this group that as psychiatry has a responsibility to treat not just an offender who is showing clinical manifestations but all offenders, the criteria of admission therefore were too narrow.

In order to resolve the question of involuntary treatment, the Centre sought and gained approval from the provincial health authority and was designated as a legitimate psychiatric facility, so that the British Columbia Mental Health Act could be applied. It was felt that those patients who are psychotic and under ordinary circumstances would be certified should be certified in the Centre and given the appropriate treatment as involuntary patients. Several authors have discussed the issue of involuntary treatment in detail (Hellack, 1974; Rappeport, 1974; Dershowitz, 1974). In this paper it is sufficient to point out that the Acts which allow civil commitment in Canada vary from province to province. In British Columbia the Act allows only detention of a patient; it does not specify involuntary treatment, therefore the dilemma is what is the purpose of applying this Act when the patient in question is already detained ?

\section{THE ISSUE OF INFORMED CONSENT}

This is a general issue in the entire field of medicine but it becomes much more important in a prison setting. It has been argued that an inmate in a prison system has so few choices that it is almost impossible for him to give informed consent for treatment. More often than not he gives consent to accept treatment with a view to obtaining secondary gain. The consent may even be part of his survival tactics in a rigid prison culture. How then can a doctor determine whether or not his patient has given informed consent?

\section{THE ISSUE OF CONFIDENTIALITY}

The doctor-patient relationship has always been considered to be one of the sacred and trusting relationships in medicine; in fact, without safeguarding this relationship medicine can hardly be practised. The question has been asked, Is it 6 possible to develop such a relationship between an inmate who is under the complete control of a gigantic criminal justice system and a doctor who is employed by the same system? Colleagues at the Centre perceived this problem acutely when they tried to treat sexual offenders. The inmate-patient appeared to be afraid to confide freely and frankly in his psychiatrist. The issues became more complex when other penal institutions wanted to 
receive full reports on the patients. It was argued that as the prison hospital was a complementary institution to the correctional service, therefore any information gained in the Centre (the status of the hospital was considered to be immaterial) should be shared by other correctional institutions which might have to deal with him in the future. When the medical personnel refused to send such reports to non-medical personnel on the grounds that medical reports are confidential and can only be released under the authority of the patient, tensions developed between the Centre and other institutions.

\section{THE ISSUE OF THE STATUS OF THE INMATE-PATIENT}

Despite the clear definition of the hospital, the Centre has become progressively embroiled in the administrative network of the Canadian Penitentiary Service. For the purpose of smooth administration the service has developed over a period of years a number of guidelines and rules which are called Commissioner's directives. These are prepared for the smooth running of the institution, keeping in mind that these documents would be used in different penitentiaries. Some of these documents clearly specify punitive procedures which should be applied in the event of certain misbehaviour by an inmate. The problem arose when some of theinmate-patients of the Abbotsford Psychiatric Centre misbehaved. Should they be punished in accordance with the administrative directives? If so, by whom? The total care of the inmate-patient lies with the physician in charge of the case and his ethics simply do not permit him to participate in any punitive procedures. While the medical personnel, including the nursing staff, understood the dilemma and took a pragmatic approach and started ignoring these misdemeanours, some of the security staff perceived such actions as neglect and permissiveness.

\section{ORGANIZATIONAL STRUCTURE AND ITS IMPLICATION IN CLINICAL CARE \\ When Dr Chalke and his colleagues made the recommendations in 1972 , they did not discuss the issue of the impact of organizational structure. It was left to the commonsense and goodwill of all persons concerned. Unfortunately conflict surfaced very soon.}

As a result of significant emphasis on the psychiatric services, the responsibilities of the then Director of Medical Services increased. By 1974 he had become the Director General of Health Care Services, and instead of reporting to the Deputy Commissioner he started reporting to the Commissioner directly. But this change in the organizational structure at the national headquarters level was not reflected at the regional level. The Director of this hospital still remained under the direct control of a regional administrator and a mythical concept of functional control was introduced. It was conceived that while the Regional Directo of controlled the administrative side of the operation of the hospital, the Director General would controi professional matters. What was missed in this argute ment is the fact that a duly licensed psychiatrist is totally and completely responsible for the care of his patient. He cannot accept professional supervisio from anyone other than the College of Physician and Surgeons of British Columbia, therefore the only real control that it is possible to exercise in. relation to this hospital must be administrative control. It seems a good management argument tot give this control to the Director General so that he can control the budgets of this hospital and als $\overline{\bar{\Xi}}$ other administrative matters which directly affect the clinical operation. Unfortunately some of the prison administrators felt very strongly that while they did not intend to interfere with the professionaf activities of the doctors, they wanted to have direct control of what services were rendered. As a result of this conflict a management consultant was appointeक to investigate the problem and make appropriat 8 recommendations to the Commissioner of Canadia Penitentiaries. At the time of writing this paper $\mathbb{\Psi}$ am not aware of a decision on this matter. However I am quite sure that an ill advised decision mighN have a significant impact on the progress that the health care services have made in Canadian prisonso

PSYCHIATRIC REPORTS AND DECISION MAKING BY TH PAROLE SERVICE

The National Parole Service of Canada continue $\stackrel{\mathbb{D}}{\stackrel{D}{ }}$ to expect a great deal of professional participatio $\overrightarrow{\vec{D}}$ from the medical professionals of the health care services. While the decision to grant parole remain the exclusive domain of the Parole Board, it is. expected that the psychiatrist will make specific recommendations and give a clear indication of hi\$ views with regard to granting parole. Consequently the psychiatrist has been placed in an unenviable position. The key issue in this matter is obviouslif the prediction of dangerousness and the psychiatrist's ability to treat criminal behaviour with any degree of success. So far the literature seems tof indicate that a psychiatrist at best can only make an:educated guess on the question of dangerousness $N$ Furthermore, experience appears to indicate that close collaboration with the National Parolf Service seems to give an impression amongst the inmates that by accepting some treatment, psychio atric or otherwise, parole can be easily obtained. Catf a doctor accept a patient under this assumption Supposing the doctor does accept a patient and finally makes a recommendation for parole to the Parole Board and they do not agree with him, then what? The inmate-patient gets bitter and blames? the psychiatrist for not pleading his case adequately? During the last four years we have encountere many such conflicts and ultimately it is the doctor-? patient relationship which is the loser. 
National conference on legal and ethical aspects of health care of prisoners

I have tried to summarize briefly some of the essential ethical dilemmas which are being faced today in the health care system of the Canadian Penitentiary Service. These dilemmas have been widely discussed amongst the professionals involved and also within the department itself. As a result of this increasing concern, the Solicitor General of Canada convened a unique national conference on the legal and ethical aspects of health care of prisoners in November 1975. The conference was held in Kingston, Ontario, under the chairmanship of the late Dr John Deutsch, former chairman of the Economic Council of Canada. The Minister invited 52 carefully chosen professionals across the country; they included the Commissioner of the Service and the Director General of the Health Care Services, psychiatrists who work within the system and some who practise outside the prisons, general practitioners, theologians, philosophers, ex-prisoners, judges, lawyers, Members of Parliament and Senators.

On 30 June 1975, in his letter of invitation, the Minister recognized the fact that the problem in the health care field in penitentiaries had become more evident and pressing as a result of a clear definition of prisoners' rights, matters of free and informed consent, civil liberties, confidentiality and the advances in medical treatment. Furthermore he indicated that the overlap with certain correctional procedures and the development of new and innovative treatments had also contributed significantly to this problem. The Chairman of the Conference identified the following objectives:

I) To ascertain the diversity to be found amongst a select and informed group of Canadians concerning the moral, legal and ethical conditions which should guide medical care for Canadian prisoners.

2) To inquire into the range of opinions which determine the varying attitudes towards the provision of health care for prisoners.

3) To advise as far as possible the Government of Canada on what is agreed to be the most acceptable guidelines for the policies, regulations and professional conduct to be expected of those responsible for providing health care in Federal correctional services.

The 52 participants gathered at the Donald Gordon Conference Centre in Kingston, Ontario, on I November 1975. For the first two days, after brief plenary sessions which reviewed the present law and health practices, the participants were divided into small groups and they were given a series of typical cases which presented complex social, ethical and legal questions. The object of such an exercise was to expose the group to practical problems which confront health professionals in the prison setting. Each group debated the cases and made appropriate recommendations which were finally gathered by a team of rapporteurs. Here is an example of a number of cases which were given to the participants.

\section{TYPICAL CASE PRESENTED TO THE CONFERENCE} DISCUSSION GROUPS

Prisoner X, well behaved and healthy, advises his cell mates that he has decided to go on a 'fast to death', because he is 'convinced he has nothing to live for'. At the next meal, he drinks only water, and after two days, the penitentiary director and the physician are advised of his continuing fast.

The Director ensures that the prisoner $\mathbf{X}$ is seen by the physician who finds him healthy and apparently stable, arranges for a psychiatric consultation and a psychological screening. At the end of a week, the prisoner is still fasting and has completed his psychological screening and psychiatric interview 'with flying colours'. The prisoner must therefore be considered as having formed an unimpaired and rational judgment, and the physician explained to him the fatal outcome of his refusal to eat, once his reserves of fat and protein had been used up. Gradually the patient became stuporous and later went into a deep coma from which he could not be roused to eat or drink.

The Declaration of Tokyo (Article 6), adopted by the 1975 General Assembly of the World Medical Association, will likely declare, in relation to treatment while imprisoned, 'the right of an individual to starve himself, provided he is capable of forming a rational judgment'. While of theoretical interest to the ethicist, it becomes of vital concern when the problem is presented to penitentiary officials who must make an immediate decision.

\section{Questions arising from the case}

I) At what stage do you consider, if ever, the physician should be required to assume any responsibility for this prisoner?

2) When prisoner $X$ lost consciousness, did a new situation develop in that he is no longer capable of a rational decision and must be revived, just as a man found hanging by the neck might be given artificial respiration, once untied ?

3) Again, if provided nourishment by intravenous and gastric tube routes until restored to a state of consciousness, when he could again communicate, must his permission then be sought to continue the process?

4) The proposed Declaration of Tokyo would avoid the problem by prohibiting artificial feeding of such an individual. Is that too simple a solution ?

5) In your opinion, would acceptance of the Tokyo Declaration (Article 6) in any way influence the responsibilities of physicians with regard to treatment of suicidal attempts involving selfinduced poisoning, hanging, gunshot or slashing of 
blood vessels?

6) If response to question 5 is no, state why not. If response to question 5 is yes, would you feel any civil, professional or criminal liability could lie with the treating professionals ?

On the final day of the conference all participants gathered and tried to form a series of recommendations and guidelines which the group would support as the ethical behaviour to be expected of the professional in the health care service. As these guidelines evolved there were varying degrees of support.

\section{The views of the philosophers}

As a unique feature of this exercise, a group of philosophers observed the deliberations of the group for the entire period, and on the final day the chairman of this group made a presentation outlining the relevant observations. Apparently the group tried an inductive method to discover the philosophical basis for ethical reasoning, both by way of agreement and disagreement. Unfortunately, the group was unable to classify or identify in any very clear way the foundations of ethical reasoning, according to any traditional schemes or categories which one could identify. However, this group of philosophers perceived a certain expressed concern amongst the participants and this concern was identified as follows: $I$ ) expediency versus the rule of law; 2) theoretical basis of informed consent and its value; 3 ) benevolence of the general obligation; 4) conflict between ethical obligation and legal rights; and 5) the moral dilemma in accepting the notion of reformation.

\section{Attempts to formulate guidelines at interna- tional level}

In the past similar attempts have been made at an international level. The working paper prepared by the Secretariat of the Vth United Nations Congress on the Prevention of Crime and the Treatment of Offenders attempted to set certain guidelines. It is worth remembering that the first UN congress on the Prevention of Crime and the Treatment of Offenders, which was held in 1955, adopted the standard minimum rules for the treatment of prisoners, but the experience of the last two decades indicates that, despite the clear expression of intent by the international community, it has not been possible to apply these rules and guidelines at an international level. The continued debate on the question of some countries abusing the medical profession as a means of social and political control is a matter of grave concern to all of us. It is hoped, however, that Canada, by maintaining an open dialogue between the criminal justice system, the public at large and the health professionals who are involved in the care of the prisoners, will set an example to the rest of the world that in providing health care services to convicted criminals one does not have to wrestle with the dilemmas of medicat ethics. If the guidelines proposed by the nation conference held in Kingston are accepted this mag be a step in the right direction.

\section{Acknowledgments}

The author wishes to express his gratitude to $\mathrm{Dr}$ I Craigen, Director General of the Medical and Health. Care Service, Canadian Penitentiary Service, Ottawa, for his permission to publish this paper. The opinions expressed herein do not necessarilg reflect the policies of the Ministry of the Solicito General of Canada.

\section{References}

An Examination of California's Prison Hospitals (1972) Assembly Select Committee on Prison Reform and Rehabilitation.

Annual Report of the Solicitor General of Canada (1970) Government of Canada, page 55.

Campbell, A V (1972). Moral Dilemmas in Medicines Churchill Livingstone, Edinburgh and London.

Chalke, F C R (1973). General Program for the Develop? ment of Psychiatric Services in Federal Correas tional Services in Canada; Information Canadऊ Government of Canada.

Cormier, M B (1973). The practice of psychiatry in the prison society. Paper presented at the Americas Academy of Psychiatry and the Law, Atlantas Georgia.

Davidson, Maurice (1957). Medical Ethics; Lloyd-Luke Medical Books Ltd. London.

Dershowitz, A M (1974). Bulletin of the American Academy of Psychiatry and the Law, 2, I72-179.

Desroches, Fred (1973). Regional psychiatric centres myopic view. Canadian fournal of Criminology, April; pp 200-218.

Erickson, Richard V (1974). Psychiatrists in prison: Oạ admitting professional tinkers into a tinker paradise. Chitty's Law fournal, 22, 29-33.

Forensic Psychiatry. Report of a Sub-Committee of this Standing Medical Advisory Committee (I969: Scottish Home and Health Department. Scottish Health Services Council, Edinburgh.

Gelfand, Michael (1968). Philosophy and Ethics Medicine; E and S Livingstone Ltd. London.

Halleck, S L (1974). Legal and ethical aspects of behaviour control. American fournal of Psychiatry, I3I, 38I-385.

McFadden, Charles J (1967). Medical Ethics; F. A Davis Co. Philadelphia.

Rappeport, J R (1974). Enforced treatment - Is if treatment? Bulletin of the American Academy of Psychiatry and the Law, 12, pp 148-158.

Report of the Canadian Committee on Correction (1969): Queen's Printers, Ottawa.

Standard Minimum Rules for the Treatment of Prison ers (1955). Resolution adopted on 30th August; ist U.N. Congress on the Prevention of Crime and this Treatment of Offenders.

Thompson, E. Ian (1976). Implications of medician ethics for ethics in general. fournal of medict ethics, 2, 74-82. 